\title{
Selection for Drought Tolerance in Wheat Population (Triticum aestivum L.) by Independent Culling Levels
}

\author{
A.A.S. Ahmed ${ }^{1, *}$, M.A. El-Morshidy ${ }^{2}$, K.A. Kheiralla ${ }^{2}$, R. Uptmoor ${ }^{3}$, M.A. Ali $^{4}$, Naheif E.M. Mohamed ${ }^{1}$ \\ ${ }^{1}$ Department of Agronomy, Faculty of Agriculture, Sohag University, Egypt \\ ${ }^{2}$ Department of Agronomy, Faculty of Agriculture, Assiut University, Egypt \\ ${ }^{3}$ Institute of Biological Production Systems, Hannover University, Germany \\ ${ }^{4}$ Department of Agronomy, Faculty of Agriculture, South Valley University, Egypt \\ *Corresponding author: tentawy@gmail.com
}

Received December 06, 2013; Revised January 25, 2014; Accepted March 23, 2014

\begin{abstract}
Field experiments were carried out at Faculty of Agriculture, Sohag University, Egypt to estimate observed and expected response to selection and genetic parameters after two cycles of phenotypic selection in $\mathrm{F}_{2}$ population. Highly significant differences among $\mathrm{F}_{3}$ and $\mathrm{F}_{4}$ families under normal and drought stress conditions for no. of spikes/plant (NS), 100-Seed weight (SW), plant height (PH), days to heading (DH) and grain yield/plant (GY) were observed. Direct response to selection for NS, SW and PH were positive and highly significant with values of 15.16, 26.34 and $6.18 \%$, respectively compared with check cultivar (Sahel 1) in $\mathrm{F}_{4}$ generation under normal conditions. Meanwhile, under drought conditions, they were 14.39, 20.35 and 6.35\%, respectively. Correlated response to selection was significant and positive for GY compared with check cultivar under two conditions. While, it was very significant and negative for HD under normal and drought stress. Expected response to selection for NS, SW and PH were (1.45 and 1.62 spikes/plant), (0.37 and $0.23 \mathrm{gm})$ and $(6.21$ and $5.90 \mathrm{~cm})$, respectively in $\mathrm{F}_{4}$ under normal and water stress conditions, respectively. High broad sense heritability values for NS, SW and PH was obtained under normal and drought stress in $\mathrm{F}_{3}$ and $\mathrm{F}_{4}$ generations. Narrow sense heritability in F4 were (48.24 and 55.31\%), (53.34 and 43.43\%) and (52.12 and 48.73\%) for NS, SW and PH, respectively, under normal and drought stress, respectively. Positive and significant correlation between three characters (no. of spikes/pant, 100 kernel weight and plant height) and grain yield/plant under normal and drought stress conditions. Thus, direct selection of these characters should be of major concern for increased grain yield under two conditions. Drought susceptibility index (DSI) showed that four families were superior for drought tolerance and had high grain yield under drought stress in $\mathrm{F}_{4}$ generations. These genotypes could be used as source of drought tolerance/or factors contributing to general adaptation.
\end{abstract}

Keywords: selection, ICL, direct response, DSI, wheat

Cite This Article: A.A.S. Ahmed, M.A. El-Morshidy, K.A. Kheiralla, R. Uptmoor, M.A. Ali, and Naheif E.M. Mohamed, "Selection for Drought Tolerance in Wheat Population (Triticum aestivum L.) by Independent Culling Levels.” World Journal of Agricultural Research, vol. 2, no. 2 (2014): 56-62. doi: 10.12691/wjar-2-2-5.

\section{Introduction}

Wheat (Triticum aestivum L.) is one of the main crops consumed by humans and it is cultivated in different environments. Drought is the single largest abiotic stress factor leading to reduced crop yields, so high-yielding crops even in environmentally stressful conditions are essential $[9,14]$. The increasing incidence and importance of drought in relation to crop production has rendered it as a major focus of research for several decades. However, studying drought response is challenged by the complex and quantitative nature of the trait. Drought tolerance is complicated with environmental interactions. In the analysis of a plant's drought response, the mode, timing, and severity of the dehydration stress and its occurrence with other abiotic and biotic stress factors are significant [24].
Although development of higher-yielding crops under water-limited environments is the most viable solution to stabilize and increase wheat production under current climatic conditions, it is challenged by the nature of drought response as a trait and the complex genomic constitution of wheat [11]. Genetic improvement for drought tolerance in wheat could be possible through conventional and mutation breeding tools. There is a strong need to identify stress tolerant genotypes which can grow and flourish well under harsh environments (low water requirements).

Independent culling levels selection is simultaneously and independently performed for all the characters. In this method, a specific level is considered for each trait and all the plants, which do not reach this level, are removed regardless of other traits. Independent culling levels is an alternative to index selection; plants are selected at a given intensity for several traits in the same generation but in sequence for each trait [16]. In wheat, morphological traits 
of aerial parts of the plant that are correlated with lodging resistance are: plant height $[4,17]$. Plant height and culm stiffness explained $77 \%$ of phenotypic variance of lodging over all three environments [17]. Lodging and grain yield were negatively correlated, while lodging and plant height were positively correlated [32].

A drought susceptibility index provides a measure of stress resistance based on minimization of yield loss under stress as compared to optimum conditions, rather than on yield level under stress per se. Drought susceptibility index has been used to characterize relative drought tolerance of wheat genotypes [5,13].

The objective of the research was to determine the effect of selection for three characters at sequential culling levels in bread wheat population under normal irrigation and drought stress conditions.

\section{Material and Methods}

The present study was carried out during the period from 2005 /06 to 2008/09 growing seasons, at Faculty of Agriculture, Sohag University, Egypt, to estimate the response to selection (i. e. pedigree selection) under normal and water stress conditions, in early generations of a bread wheat (Triticum aestivum L. em. Thel) population originated from the cross between Sids 4 and Tokwie (Table 1). The genetic parameters were estimated in $F_{3}$ and $\mathrm{F}_{4}$ generations.

Table 1. The pedigree and origin of the two parents and the tolerant cultivar (Sahel 1)

\begin{tabular}{ccc}
\hline Parental name & Pedigree & Origin \\
\hline Sids 4 (P1) & May'S'/Mon'S'//CMH74A.592/3/ & Egypt \\
Tokwie (P2) & Giza 157*2 & South Africa \\
Sahel 1 & NS 732/PIMA//Veery'S' & ICARDA \\
\hline
\end{tabular}

In the 2005 / 06 season, 1000 plants of $F_{2}$ generation were grown in four non-replicated plots. Each plot consisted of 12 rows $3 \mathrm{~m}$ long, $20 \mathrm{~cm}$ apart and grain spaced $10 \mathrm{~cm}$ within row (30 individual plant/row). Also, the parents and the local check (Sahel 1, drought tolerant) were grown alongside each a row. The soil was fertilized at the rate of $20 \mathrm{~kg} / \mathrm{fed}\left(15 \% \mathrm{P}_{2} \mathrm{O}_{5}\right)$ and $80 \mathrm{~kg} / \mathrm{fed}(33.5 \%$ ammonium nitrate) and weeds were controlled by hand. Data were collected on 600 harvested plants. Data were recorded on number of days to heading (DH), plant height (PH), No of spikes/plant(NS), 100-Seed weight (SW) and grain yield/plant (GY) for each individual plant. Sixty plants for independent culling levels selection (ICL) based on three characters (high NS, high SW and best $\mathrm{PH}$ ) were selected from the $F_{2}$ generation. An equal number of grains from each plant (600 plants) were bulked to give $F_{3}$ random bulk sample.

In the 2006/07 season, two field experiments were conducted each in a randomized complete block design of four replications. The first experiment did not receive any irrigation after jointing stage (drought stress “D”), while the other one was grown in supplemental water when ever required to harvest (Normal irrigated condition “N”). Each selected plant from the $F_{2}$ generation was planted in the two experiments. Each experiment comprised $60 \mathrm{~F}_{3}$ families. The 22 families were selected on the basis of independent culling selection (high NS, high SW and best
PH, from 110 to120 cm under normal and from 100 to 110 $\mathrm{cm}$ under drought stress, to give good straw weight with resistance of lodging). An equal number of grains composted from each $F_{3}$ plant to gave $F_{4}$ bulk progenies in addition to the parents and the check.

In 2007/08 season ( $F_{4}$ generation), two field experiments were conducted as in the previous season. The selected families from the $F_{3}$ generation were evaluated under stressed and normal irrigated conditions; along with the two parents, bulk sample and the check cultivar Sahel 1.

Statistical procedures:

1. Analysis of variance (Table 2) for randomized complete block design was carried out according to [28].

2. The genotypic variance $\sigma 2 \mathrm{~g}=\mathrm{M}_{2}-\mathrm{M}_{1} / \mathrm{r}$

3. The phenotypic variance $\sigma 2 \mathrm{p}=\sigma 2 \mathrm{~g}+\sigma 2 \mathrm{e}$

4. The genotypic (G.C.V\%) and phenotypic (P.C.V\%) coefficients of variability were calculated as $\sigma \mathrm{g} / \bar{x}$ and $\sigma \mathrm{p} / \bar{x}$, respectively.

5. Heritability in the broad sense $(\mathrm{H})$ was estimated as the ratio of genotypic $\left(\sigma^{2} \mathrm{~g}\right)$ to the phenotypic $\left(\sigma^{2} \mathrm{~g}+\right.$ $\left.\sigma^{2} \mathrm{e}\right)$ variance [32].

Table 2. The analysis of variance and expected means of squares

\begin{tabular}{cccc}
\hline SOV & D.F & M.S & E.M.S \\
\hline Replication & $\mathrm{r}-1$ & $\mathrm{M}_{3}$ & $\sigma^{2} \mathrm{e}+\mathrm{g} \sigma^{2} \mathrm{r}$ \\
Genotypes & $\mathrm{g}-1$ & $\mathrm{M}_{2}$ & $\sigma^{2} \mathrm{e}+\mathrm{r} \sigma^{2} \mathrm{~g}$ \\
Error & $(\mathrm{r}-1)(\mathrm{g}-1)$ & $\mathrm{M}_{1}$ & $\sigma^{2} \mathrm{e}$ \\
\hline
\end{tabular}

6 . Heritability in the narrow sense was estimated using the correlation and offspring regression according to [27].

7. The genetic parameters were estimated as outlined by $[10,20]$.

8. Mean comparisons were calculated by using revised L.S.D where, L.S.D = least significant difference, and was calculated as:

$$
\operatorname{RLSD} \alpha=(\mathrm{t}-) \alpha * \sqrt{\left(2 \mathrm{MS}_{\mathrm{E}} / \mathrm{r}\right)}[8] .
$$

9. The significance of observed direct and correlated response to selection was measured as deviation percentage of families mean from the bulk or the better parent or the check using L. S. D. where, L.S.D = least significant differences between the bulk or the better parent or the check values and mean of the selected families, and was calculated as:

$$
\text { L. S. D }=\sqrt{\left(\mathrm{MS}_{\mathrm{E}} / \mathrm{r}+\mathrm{MS}_{\mathrm{E}} / \mathrm{fr}\right)} * \mathrm{t} \alpha
$$

where $\mathrm{f}$ : number of families r: number of replicates. where $\mathrm{t}$ - is the $\mathrm{t}$ value from "minimum-average-risk t-table" at Fvalue of treatments, treatment $\mathrm{df}$ and experimental error $\mathrm{df}$.

10. Drought susceptibility Index (S): was calculated according to the method of [13].

\section{Results and Discussion}

\subsection{Evaluation of the Base Population ( $F_{2}$ Plants)}

The results in Table 3 showed that Number of days to $50 \%$ heading ranged from 74.00 to 97.00 days with an average of 82.98 days and variation coefficient was $5.91 \%$ 
in $F_{2}$ plants under normal conditions (Figure 1 a). The average number of spikes/plant was 5.28 spikes/plant with a range from 2.00 to 11.00 spikes/plant and variation coefficient was 33.84\% (Figure 1 b). 100-Seed weight ranged from 2.00 to $5.26 \mathrm{gm}$ with an average of $3.99 \mathrm{gm}$ and coefficient of variation was $11.89 \%$ (Figure $1 \mathrm{c}$ ). Mean plant height was $117.71 \mathrm{~cm}$ with a range from 85.00 to $148.00 \mathrm{~cm}$ and variation coefficient was $10.77 \%$ (Figure d). Average grain yield/plant ranged from 1.36 to $16.62 \mathrm{gm}$ with an average of $7.70 \mathrm{gm}$ and coefficient of variation was $39.29 \%$ (Figure 1 e).
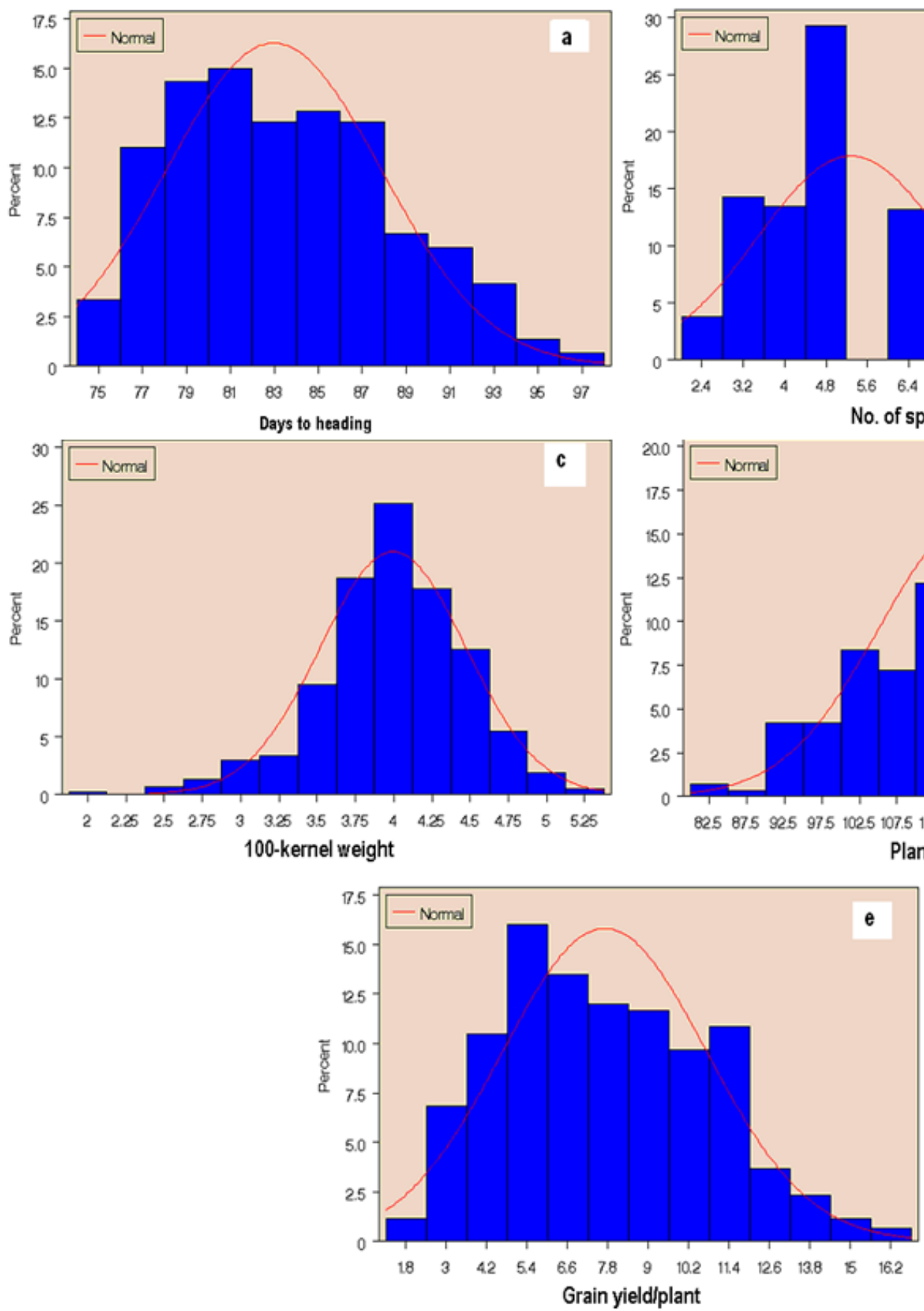

Figure 1. (a, b, c, d and e) shows the normal distribution of DH, NS, SW, PH and GY as traits on the $\mathrm{F}_{2}$ plants under normal irrigated conditions

\subsection{The Response to Direct Selection for ICL under Normal and Water Stress Conditions}

Variance and means: The analysis of variance for NS, SW and PH (Table 4) showed highly significant
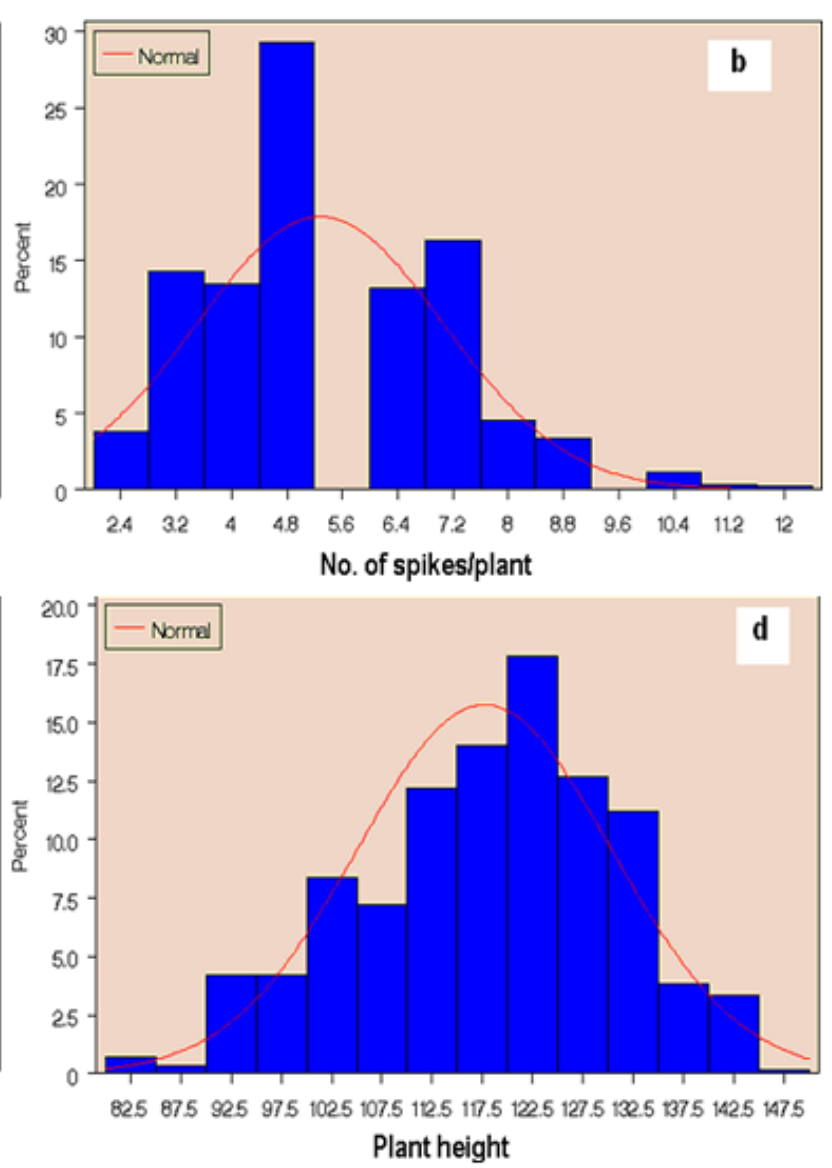

Table 3. Range, mean and coefficient of variation in $\mathrm{F}_{2}$ plants for $\mathrm{PH}$ NS, SW, DH and GY under normal conditions

\begin{tabular}{cccc}
\hline Trait & Range & Means \pm S.E & C.V. \% \\
\hline PH & $85.00-148.00$ & $117.71 \pm 0.52$ & 10.77 \\
NS & $2.00-11.00$ & $5.28 \pm 0.07$ & 33.84 \\
SW & $2.00-5.26$ & $3.99 \pm 0.02$ & 11.89 \\
DH & $74.00-97.00$ & $82.98 \pm 0.20$ & 5.91 \\
GY & $1.36-16.62$ & $7.70 \pm 0.12$ & 39.29 \\
\hline
\end{tabular}

differences among $\mathrm{F}_{3}$ and $\mathrm{F}_{4}$ families under normal and water stress conditions. These results suggest that selection for each of these traits will be effective, in addition great response to selection can be achieved from selection in such population having a large amount of phenotypic and genotypic variance [18,35]. Ref. [34] 
reported that although response to selection will be greater in population with great genetic variance.

Table 4. Mean squares for all studied traits in $\mathrm{F}_{3}$ and $\mathrm{F}_{4}$ of ICL families of under normal (N) and drought stress conditions (D)

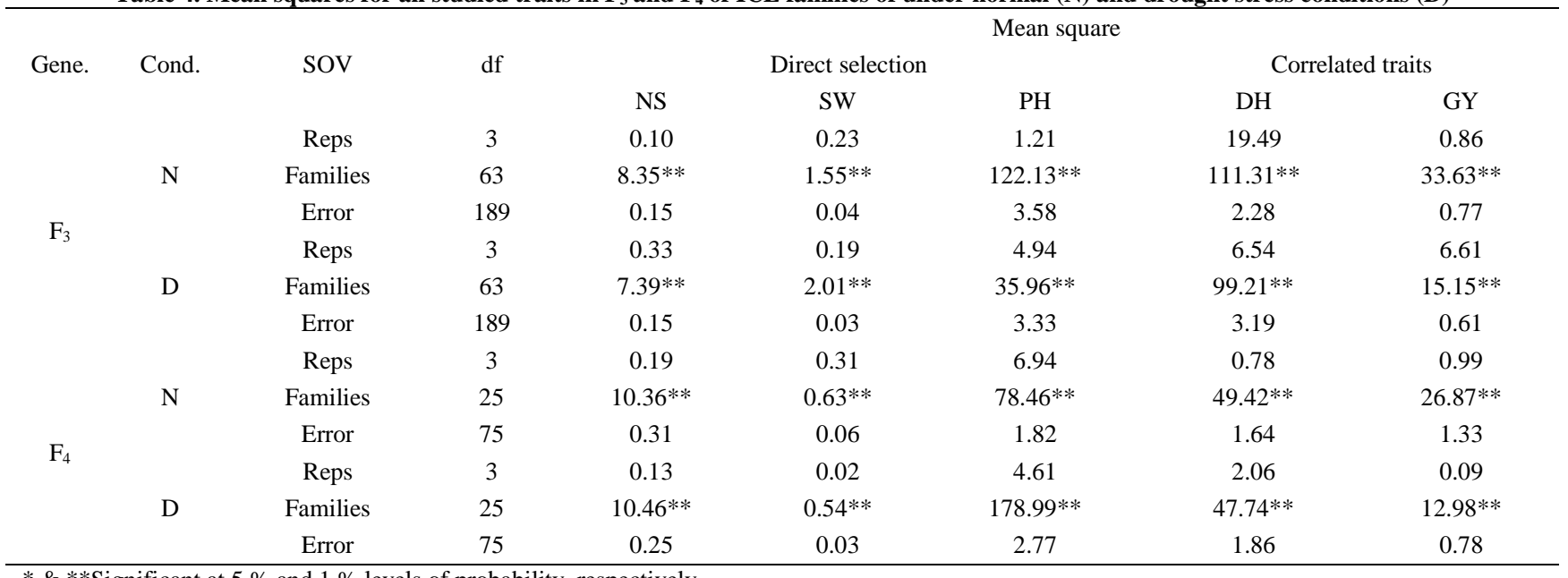

* \& **Significant at $5 \%$ and $1 \%$ levels of probability, respectively.

The results showed (Table 5) that two families, i.e., no. 6 and 25 under normal condition and four families (no. 6, 13, 25 and 45) under drought condition were significantly higher than the better parent in NS. While, twelve families, i.e., no. $6,13,19,25,36,37,39,42,43,45,46$ and 55 surpassed the check under normal and drought stress conditions in NS. Ten families, i.e., no. 6, 22, 23, 24, 25, 28, 33, 37, 42, and 45 under drought condition were

significantly higher than the better parent in SW. Meanwhile, all selected families surpassed the check under drought condition except (no. 55) n SW. While, fourteen families, i.e., no. 1, 13, 19, 22, 23, 24, 25, 36, 37, $38,39,43,46$ and 55 were suitable $\mathrm{PH}$ to give good straw weight with resistance of lodging under normal and drought stress conditions $[17,33]$.

Table 5. Mean grain yield and correlated traits of independent culling levels families in $\mathbf{F}_{4}$ generation under normal and drought stress condition

\begin{tabular}{|c|c|c|c|c|c|c|c|c|c|c|}
\hline \multirow{3}{*}{$\begin{array}{l}\text { Selected } \\
\text { families }\end{array}$} & \multicolumn{5}{|c|}{ Normal irrigation } & \multicolumn{5}{|c|}{ Drought stress } \\
\hline & \multicolumn{3}{|c|}{ Selection criteria } & \multicolumn{2}{|c|}{ Correlated traits } & \multicolumn{3}{|c|}{ Selection criteria } & \multicolumn{2}{|c|}{ Correlated traits } \\
\hline & NS & SW & $\mathrm{PH}$ & $\mathrm{DH}$ & GY & NS & SW & $\mathrm{PH}$ & $\mathrm{DH}$ & GY \\
\hline 1 & 8.45 & 5.09 & 118.90 & 83.50 & 19.21 & 6.35 & 4.72 & 109.70 & 82.75 & 14.51 \\
\hline 6 & 11.40 & 5.98 & 129.60 & 79.00 & 26.32 & 10.35 & 5.24 & 110.90 & 78.25 & 16.28 \\
\hline 13 & 10.70 & 4.95 & 115.65 & 75.75 & 21.44 & 9.75 & 4.41 & 104.25 & 75.00 & 14.91 \\
\hline 19 & 9.05 & 5.33 & 118.60 & 82.50 & 20.69 & 8.70 & 4.83 & 109.55 & 81.25 & 17.23 \\
\hline 22 & 7.60 & 5.78 & 122.95 & 76.00 & 20.51 & 7.00 & 5.03 & 110.65 & 75.75 & 17.43 \\
\hline 23 & 7.35 & 5.91 & 121.30 & 79.50 & 18.45 & 6.85 & 5.41 & 111.10 & 78.00 & 13.13 \\
\hline 24 & 6.00 & 5.43 & 111.15 & 77.25 & 19.35 & 5.00 & 5.18 & 111.30 & 76.50 & 16.37 \\
\hline 25 & 11.20 & 5.44 & 114.95 & 78.25 & 21.50 & 10.55 & 4.93 & 101.15 & 77.25 & 17.39 \\
\hline 26 & 8.50 & 5.10 & 124.80 & 80.75 & 18.69 & 6.75 & 4.61 & 105.15 & 80.00 & 14.99 \\
\hline 28 & 8.05 & 5.76 & 134.00 & 76.00 & 21.24 & 7.03 & 5.06 & 111.55 & 75.00 & 15.11 \\
\hline 33 & 8.35 & 5.91 & 118.10 & 75.75 & 21.32 & 7.75 & 5.35 & 115.75 & 75.25 & 17.70 \\
\hline 36 & 9.85 & 5.03 & 119.15 & 80.75 & 24.30 & 8.65 & 4.45 & 105.35 & 79.75 & 13.82 \\
\hline 37 & 10.60 & 5.61 & 122.10 & 69.00 & 19.72 & 9.00 & 5.06 & 111.30 & 68.00 & 15.59 \\
\hline 38 & 8.05 & 5.11 & 114.65 & 78.75 & 21.31 & 7.50 & 4.60 & 111.00 & 78.00 & 17.45 \\
\hline 39 & 9.00 & 5.33 & 117.15 & 85.25 & 20.18 & 8.00 & 4.48 & 103.50 & 84.50 & 15.17 \\
\hline 42 & 9.65 & 5.22 & 129.00 & 78.75 & 21.30 & 8.00 & 4.89 & 105.80 & 78.25 & 14.28 \\
\hline 43 & 9.05 & 5.14 & 116.20 & 80.75 & 22.21 & 8.50 & 4.55 & 108.75 & 80.25 & 16.01 \\
\hline 45 & 10.45 & 5.87 & 132.10 & 78.00 & 26.55 & 9.88 & 4.88 & 105.95 & 77.25 & 19.37 \\
\hline 46 & 9.65 & 5.88 & 115.15 & 81.00 & 24.50 & 8.50 & 4.66 & 109.10 & 80.00 & 14.79 \\
\hline 48 & 8.10 & 5.25 & 123.60 & 76.50 & 18.85 & 6.65 & 4.18 & 113.75 & 76.25 & 14.94 \\
\hline 55 & 9.00 & 5.31 & 116.30 & 77.25 & 20.09 & 7.80 & 4.66 & 108.85 & 76.75 & 13.20 \\
\hline 62 & 8.90 & 4.87 & 112.30 & 78.75 & 18.11 & 6.25 & 4.21 & 97.65 & 78.00 & 12.40 \\
\hline Average & 9.04 & 5.42 & 120.35 & 78.59 & 21.17 & 7.95 & 4.79 & 108.28 & 77.82 & 15.55 \\
\hline P1 & 4.05 & 5.60 & 105.35 & 71.75 & 17.46 & 3.60 & 4.62 & 96.10 & 71.25 & 13.11 \\
\hline P2 & 10.15 & 5.26 & 123.85 & 80.00 & 18.16 & 9.10 & 4.50 & 114.05 & 79.50 & 13.90 \\
\hline Bulk & 7.70 & 5.20 & 118.50 & 75.25 & 16.80 & 6.30 & 4.36 & 104.10 & 75.00 & 12.72 \\
\hline Sahel 1 & 7.85 & 4.29 & 113.35 & 82.50 & 17.08 & 6.95 & 3.98 & 102.30 & 81.75 & 13.38 \\
\hline RLSD $_{0.05}$ & 0.69 & 0.32 & 1.67 & 1.58 & 1.51 & 0.62 & 0.23 & 2.06 & 1.73 & 1.16 \\
\hline RLSD $_{0.01}$ & 0.90 & 0.42 & 2.18 & 2.12 & 1.91 & 0.81 & 0.30 & 2.70 & 2.21 & 1.46 \\
\hline
\end{tabular}

The observed and expected responses to selection of the 6 . The observed response to selection for NS compared independent culling levels selection are presented in Table with bulk, better parent and check (Sahel 1) were (17.40, - 
10.94 and $15.16 \%)$ and (26.19, -12.64 and $14.39 \%)$ in $\mathrm{F}_{4}$ families under normal and drought conditions, respectively. The observed response for SW were (22.45, -3.21 and $26.34 \%)$ and (9.86, 3.38 and $20.35 \%$ ) in F4 families under normal and water stress conditions, respectively. Meanwhile, the observed response for $\mathrm{PH}$ were (1.56, 14.24 and $6.18 \%$ ) and (4.51, -4.60 and $6.35 \%$ ) in $F_{4}$ families under normal and drought stress conditions, respectively. Moreover, the observed direct response to selection for NS and SW resulted in positive and highly significant observed gain compared with bulk and the check (Sahel 1) under normal and drought stress environments. On the other hand, the expected responses to selection for NS, SW and PH, respectively, were (12.75 and 16.20\%), (5.46 and 3.74\%) and (4.94 and 4.31\%) in F4 families under normal and drought stress conditions, respectively. Similar results were reported by $[2,6,7,18,21,23,29,30]$. Indirect selection based upon one or more of yield components, i.e., NS and SW might be more effective than direct selection for GY itself [36].

Table 6. The observed and expected responses to selection in $\mathrm{F}_{4}$ generation for all studied traits of ICL families under normal (N) and drought (D) conditions

\begin{tabular}{|c|c|c|c|c|c|c|c|c|c|}
\hline & & \multicolumn{8}{|c|}{ Response to selection as deviation from } \\
\hline \multicolumn{2}{|c|}{ Trait } & \multicolumn{2}{|c|}{ Bulk } & \multicolumn{2}{|c|}{ Best patent } & \multicolumn{2}{|c|}{ Check (Sahel 1) } & \multicolumn{2}{|c|}{ Expected response } \\
\hline & & unit & $\%$ & unit & $\%$ & unit & $\%$ & unit & $\%$ \\
\hline \multicolumn{10}{|c|}{ Direct response } \\
\hline \multirow{3}{*}{ NS } & $\mathrm{N}$ & $1.34 * *$ & $17.40^{* *}$ & $-1.11 * *$ & $-10.94 * *$ & $1.19 * *$ & $15.16 * *$ & 1.15 & 12.75 \\
\hline & $\mathrm{D}$ & $1.65^{* *}$ & $26.19 * *$ & $-1.15^{* *}$ & $-12.64 * *$ & $1.00 * *$ & $14.39 * *$ & 1.29 & 16.20 \\
\hline & $\mathrm{N}$ & $0.43^{* *}$ & $9.86^{* *}$ & 0.17 & $3.68 * *$ & $0.81^{* *}$ & $20.35 * *$ & 0.18 & 3.74 \\
\hline \multirow[t]{2}{*}{ SW } & $\mathrm{D}$ & 0.22 & $22.45^{* *}$ & -0.18 & $-3.21^{* *}$ & $1.13^{* *}$ & $26.34 * *$ & 0.30 & 5.45 \\
\hline & $\mathrm{N}$ & $4.70 * *$ & $4.51^{* *}$ & $-5.25 * *$ & $-4.60 * *$ & $6.50 * *$ & $6.35^{* *}$ & 4.69 & 4.31 \\
\hline \multirow[t]{2}{*}{$\mathrm{PH}$} & $\mathrm{D}$ & $1.85^{* *}$ & $1.56^{*}$ & $15.00 * *$ & $14.24 * *$ & $7.00 * *$ & $6.18^{* *}$ & 4.94 & 4.94 \\
\hline & \multicolumn{9}{|c|}{ Correlated response in } \\
\hline \multirow{3}{*}{ DH } & $\mathrm{N}$ & $3.34 * *$ & $4.44^{* *}$ & $6.84^{* *}$ & $9.53^{* *}$ & $-3.91 * *$ & $-4.74 * *$ & 1.44 & 1.84 \\
\hline & $\mathrm{D}$ & $2.82^{* *}$ & $3.76^{* *}$ & $6.57 * *$ & $9.22 * *$ & $-3.93 * *$ & $-4.81^{* *}$ & 1.38 & 1.77 \\
\hline & $\mathrm{N}$ & $2.83^{* *}$ & $22.25^{* *}$ & $1.65^{* *}$ & $11.87 * *$ & $2.17 * *$ & $16.22 * *$ & 1.67 & 10.75 \\
\hline GY & $\mathrm{D}$ & $4.37 * *$ & $26.01 * *$ & $3.01^{* *}$ & $16.57 * *$ & $4.09 * *$ & $23.95 * *$ & 1.91 & 9.00 \\
\hline
\end{tabular}

Phenotypic, genotypic coefficients of variability and heritability: The phenotypic (P.C.V. \%) and genotypic (G.C.V. \%) coefficients of variation (Table 7) for NS in $\mathrm{F}_{3}$ families were 36.40 and $29.16 \%$ under normal conditions, respectively as well as they were 42.84 and $37.02 \%$ under drought conditions, respectively. While, in $\mathrm{F}_{4}$ generation, they were 43.99 and $36.19 \%$ under normal conditions, respectively as well as they were 46.89 and $39.48 \%$ under drought stress conditions, respectively. The phenotypic variability (p.c.v. \%) for SW under drought stress was $2.09 \%$ in $\mathrm{F}_{3}$ and $3.76 \%$ in $\mathrm{F}_{4}$ families, Meanwhile it was under normal conditions 4.66 and $7.68 \%$ in $\mathrm{F}_{3}$ and $\mathrm{F} 4$ families, respectively. But the genotypic variability (g.c.v \%) under drought stress was 1.38 in $F_{3}$ and $2.89 \%$ in F4 families, while under normal conditions it was 3.42 and $6.12 \%$ in the $F_{3}$ and $F_{4}$ generations, respectively. Meanwhile, the phenotypic values (p.c.v) for $\mathrm{PH}$ under normal conditions were 33.22 and $45.98 \%$ in the $\mathrm{F}_{3}$ and $\mathrm{F}_{4}$ generations, respectively. While it was 36.49 and 46.83\% in $F_{3}$ and $F_{4}$ generations under drought stress, respectively. Moreover, the magnitude of genotypic variability was $29.64 \%$ in $\mathrm{F}_{3}$ and $44.16 \%$ in $\mathrm{F}_{4}$ generation under normal conditions, while it was 33.16 and $44.06 \%$ in $\mathrm{F}_{3}$ and $\mathrm{F}_{4}$ generations under drought stress, respectively. These results are in harmony with $[3,7,19,21,30]$. Greater response to selection can be expected from selection in population having greater phenotypic and genotypic variance [18,34,35].

The broad sense heritability (Table 7) under normal and drought stress for NS, SW and $\mathrm{PH}$ in $\mathrm{F}_{3}$ generation were (80.09 and $86.43 \%)$, (73.36 and 65.96\%) and (89.23 and $90.87 \%)$, respectively. While in $\mathrm{F}_{4}$ generation they were (82.27 and $84.20 \%)$, (79.66 and 76.76\%) and (96.04 and $94.09 \%$ ) for the same traits, respectively, indicating that environmental effects were small as compared to the genetic effects. While narrow sense heritability in $F_{4}$ generation under normal and drought stress were (48.24 and 55.31\%), (53.34 and 43.43\%) and (52.12 and 48.73\%) for NS, SW and $\mathrm{PH}$, respectively. These results are in line with those obtained by $[3,7,25,30]$.

Table 7. The genetic parameters of NS, SW and PH in $F_{3}$ and $F_{4}$ generations of ICL families under normal and drought conditions

\begin{tabular}{|c|c|c|c|c|c|c|c|c|c|c|c|c|}
\hline \multirow{3}{*}{ Items } & \multicolumn{4}{|c|}{ NS } & \multicolumn{4}{|c|}{ SW } & \multicolumn{4}{|c|}{ PH } \\
\hline & \multicolumn{2}{|c|}{ Normal } & \multicolumn{2}{|c|}{ Drought } & \multicolumn{2}{|c|}{ Normal } & \multicolumn{2}{|c|}{ Drought } & \multicolumn{2}{|c|}{ Normal } & \multicolumn{2}{|c|}{ Drought } \\
\hline & $F_{3}$ & $\mathrm{~F}_{4}$ & $\mathrm{~F}_{3}$ & $\mathrm{~F}_{4}$ & $\mathrm{~F}_{3}$ & $\mathrm{~F}_{4}$ & $\mathrm{~F}_{3}$ & $\mathrm{~F}_{4}$ & $\mathrm{~F}_{3}$ & $\mathrm{~F}_{4}$ & $\mathrm{~F}_{3}$ & $\mathrm{~F}_{4}$ \\
\hline pheno. Var. & 36.40 & 43.99 & 42.84 & 46.89 & 4.66 & 7.68 & 2.09 & 3.76 & 33.22 & 45.98 & 36.49 & 46.83 \\
\hline Geno. Var. & 29.16 & 36.19 & 37.02 & 39.48 & 3.42 & 6.12 & 1.38 & 2.89 & 29.64 & 44.16 & 33.16 & 44.06 \\
\hline P.C.V. \% & 14.69 & 13.64 & 18.97 & 16.60 & 14.57 & 13.40 & 13.32 & 12.43 & 4.98 & 5.68 & 5.72 & 6.36 \\
\hline G.C.V. \% & 13.15 & 12.37 & 17.64 & 15.23 & 12.48 & 11.96 & 10.82 & 10.89 & 4.71 & 5.56 & 5.46 & 6.15 \\
\hline Heritability & & & & & & & & & & & & \\
\hline Broad-sense & 80.09 & 82.27 & 86.43 & 84.20 & 73.36 & 79.66 & 65.96 & 76.76 & 89.23 & 96.04 & 90.87 & 94.09 \\
\hline Narrow-sense & -- & 48.24 & -- & 55.31 & -- & 53.34 & -- & 43.43 & -- & 52.12 & -- & 48.73 \\
\hline
\end{tabular}




\subsection{Effects of Selection for ICL under Normal and Water Stress Conditions on Correlated Traits}

\subsubsection{Variance and Means}

Analysis of variance (Table 4) for DH and GY revealed highly significant differences in $F_{3}$ and $F_{4}$ generations under the two environments.

Data in Table 3 presented the range and average of $F_{4}$ generation under normal and water stress conditions for the correlated traits. The average $\mathrm{DH}$ in $\mathrm{F}_{4}$ generation ranged from 69.00 to 85.25 with an average of 78.59 days and from 68.00 to 84.50 with an average of 77.82 days under the two environmental conditions, respectively. Meanwhile, the averages of DH were 75.25, 71.75 and 82.50 days for bulk population, early parent and check (Sahel 1), respectively under normal condition and were 75.00, 71.25 and 81.75 days for bulk population, early parent and check, respectively under drought condition.

The results in Table 5 indicated that all selected families except (no. 1, 19, 39 and 46) under non-stress condition and all selected families except (no. 1, 19, 39 and 43) under stress condition for DH were significantly earlier than the check (Sahel 1). Moreover, the value of earliness in significantly families for $\mathrm{DH}$ was 1.17 days for family no. 37 and was 1.52 days for family no. 37 compared with earlier parent under normal and drought stress conditions. While, one family, i.e., no. 37 under normal and drought conditions were significantly earlier than the earlier parent. Furthermore, they varied from 0.17 days for family no. 26 or 36 or 43 to 11.92 days for family no. 37 and from 0.02 days for family no. 26 or 46 to 12.02 days for family no. 37 compared with the check (Sahel 1) under normal and drought conditions, respectively.

GY in $F_{4}$ generation (Table 3) ranged from 16.80 to 26.55 with an average of $21.17 \mathrm{~g} /$ plant and from 12.40 to 19.37 with an average of $15.55 \mathrm{~g} /$ plant under the two environments, respectively. Meanwhile, the average of GY for bulk population, better parent and check were (16.80, 18.16 and 17.08) and (12.72, 13.90 and 13.38) under normal and drought conditions, respectively.

All selected families (Table 5) under normal condition except (no. 1, 23, 24, 26, 48 and 62) and all selected families under drought stress conditions except (no. 1, 13, 23, 26, 36, 42, 46, 48, 55 and 62) for GY were significantly out-yielded the better parent. While, all selected families under normal condition except (no. 23 and 62) and all selected families under stress condition except (no. 1, 23, 36, 42, 55 and 62) were significantly higher than the check.

Moreover, the values of grain yield in significantly families varied from 0.05 gm for family no. 37 to $6.88 \mathrm{gm}$ for family no. 45 and from 0.05 gm for family no. 28 to $4.31 \mathrm{gm}$ for family no. 45 compared with better parent under normal and drought environments, respectively. Meanwhile, they varied from 0.10 gm for family no. 26 to 7.96 gm for family no. 45 and from 0.25 gm for family no. 46 to 4.83 gm for family no. 45 compared with the check under normal and drought environments, respectively.

Correlation: positive and significant correlation (Table 8) between three characters (NS, SW and PH) and GY under normal and drought stress conditions in $F_{4}$ generation. Thus, direct selection of these characters should be major concern for increased GY under two conditions. Meanwhile, negative and significant correlation between SW and $\mathrm{DH}$, in the same time, no significant between two characters (NS and $\mathrm{PH}$ ) and $\mathrm{DH}$ $[3,26,30]$.

Table 8. Correlation between three characters (NS, SW and PH) and $\mathrm{GY}$ and $\mathrm{DH}$ in $\mathrm{F}_{4}$ generation under normal and drought conditions

\begin{tabular}{|c|c|c|c|c|}
\hline \multicolumn{2}{|c|}{ Traits } & NS & SW & $\mathrm{PH}$ \\
\hline \multirow{2}{*}{ GY } & $\mathrm{N}$ & $0.61^{* *}$ & $0.51 * *$ & $0.43^{* *}$ \\
\hline & $\mathrm{D}$ & $0.47 * *$ & $0.52 * *$ & $0.26 *$ \\
\hline \multirow{2}{*}{$\mathrm{DH}$} & $\mathrm{N}$ & NS & $-0.34 * *$ & NS \\
\hline & $\mathrm{D}$ & NS & $-0.22 *$ & NS \\
\hline
\end{tabular}

Drought susceptibility index (DSI): The values of DSI for families selected for independent culling levels (Table 9) ranged from 0.69 to 1.31 and from 0.56 to 1.60 in $\mathrm{F}_{3}$ and $\mathrm{F}_{4}$ generations, respectively.

Table 9. The drought susceptibility index (DSI) and grain yield (GY) of Families selected for independent culling levels in F3 and F4 generations

\begin{tabular}{ccccccc} 
selected & \multicolumn{3}{c}{$\mathrm{F}_{3}$ generation } & \multicolumn{5}{c}{ F $_{4}$ generation } \\
families & $\mathrm{GY}$ & $\mathrm{G}$ & $\mathrm{G}$ ( & $\mathrm{N}$ & $\mathrm{D}$ & $\mathrm{DSI}$ \\
1 & 15.61 & 11.08 & 1.00 & 19.21 & 14.51 & 0.91 \\
6 & 19.55 & 12.83 & 1.19 & 26.32 & 16.28 & 1.41 \\
13 & 18.11 & 12.82 & 1.01 & 21.44 & 14.91 & 1.13 \\
19 & 14.42 & 11.45 & 0.71 & 20.69 & 17.23 & 0.62 \\
22 & 14.97 & 11.99 & 0.69 & 20.51 & 17.43 & 0.56 \\
23 & 15.54 & 11.03 & 1.00 & 18.45 & 13.13 & 1.07 \\
24 & 16.40 & 12.83 & 0.75 & 19.35 & 16.37 & 0.57 \\
25 & 17.85 & 13.93 & 0.76 & 21.50 & 17.39 & 0.71 \\
26 & 14.60 & 10.75 & 0.91 & 18.69 & 14.99 & 0.73 \\
28 & 17.44 & 10.94 & 1.29 & 21.24 & 15.11 & 1.07 \\
33 & 16.26 & 12.89 & 0.71 & 21.32 & 17.70 & 0.63 \\
36 & 15.60 & 10.34 & 1.16 & 24.30 & 13.82 & 1.60 \\
37 & 15.64 & 10.78 & 1.07 & 19.72 & 15.59 & 0.78 \\
38 & 15.74 & 12.29 & 0.76 & 21.31 & 17.45 & 0.67 \\
39 & 16.82 & 10.84 & 1.23 & 20.18 & 15.17 & 0.92 \\
42 & 19.44 & 12.50 & 1.23 & 21.30 & 14.28 & 1.22 \\
43 & 17.59 & 10.91 & 1.31 & 22.21 & 16.01 & 1.03 \\
45 & 18.90 & 13.12 & 1.05 & 26.55 & 19.37 & 1.00 \\
46 & 15.70 & 10.76 & 1.09 & 24.50 & 14.79 & 1.47 \\
48 & 14.20 & 10.95 & 0.79 & 18.85 & 14.94 & 0.77 \\
55 & 14.75 & 10.86 & 0.91 & 20.09 & 13.20 & 1.27 \\
62 & 12.97 & 9.16 & 1.01 & 18.11 & 12.40 & 1.17 \\
\hline
\end{tabular}

The results showed that nine families in $\mathrm{F}_{3}$ and eleven in $\mathrm{F}_{4}$ generation gave low values of drought susceptibility index (DSI $<1$ ), while the eight families, i.e., no 19,22 , 24, 25, 26, 33, 38 and 48 produced the low values of susceptibility index in $F_{3}$ and $F_{4}$. Superior families for drought tolerance of the selected families gave low values of drought susceptibility index and the highest grain yield under drought, these families (Tables 5 and 9) were no. 24, 25, 33 and 38 in $F_{3}$ and $F_{4}$ generations and no. 19, 22, 37 and 39 in $\mathrm{F}_{4}$ generation. These genotypes could be used as source of drought tolerance / or factors contributing to general adaptation. These results are in agreement with those obtained by $[1,12,15,18,22,31]$. These results were confirmed by high heritability, high response to selection and more identified superior lines under normal and drought stress conditions in latter generations due to selection for independent culling levels in early generations. 


\section{References}

[1] Aliakbari, M., A. Saed-Moucheshi, H. Hasheminasab, H. PirastehAnosheh, M. T. Asad and Y. Emam, 2013.Suitable Stress Indices for Screening Resistant Wheat Genotypes under Water Deficit Conditions. International journal of Agronomy and Plant Production. Vol., 4 (10): 2665-2672.

[2] Amin, M.R., N.C.D. Barma and M. A. Razzaque. 1992. Variability, heritability, genetic advance and correlation study in some quantitative characters in durum wheat. Rachis, 11(1/2): 30 32.

[3] Attia, I.A. 2003. Selection for drought tolerance in wheat. Ph.D. Thesis, El-Minia Univ., Egypt.

[4] Berry, P.M., R. Sylvester-Bradley, 2007. Ideotype design for lodging-resistant wheat. Euphytica, 154: 165-179.

[5] Clarke, J.M., T. F. Townley-Smith, T.N. McCaig and D. G. Green. 1984. Growth analysis of spring wheat cultivars of varying drought resistance. Crop Sci., 24:537-541.

[6] Donmez, E.R., R.G. Sears, J.P. Shroyer and G.M. Paulsen. 2001. Genetic gain in yield attributes of winter wheat in the great plains. Crop Sci., 41:1412-1419.

[7] Ehdaie, B., and J.G. Waines, 1989. Genetic variation, heritability, and path-analysis in landraces of bread wheat from South Western Iran. Euphytica, 41:183-190.

[8] El-Rawi, K. and A.M. Khalafalla. 1980. Design and analysis of agricultural experiments, El Mousel Univ., Iraq, 19.

[9] Ergen, N. Z. and H. Budak, 2009. Sequencing over 13000 expressed sequence tags from six subtractive cDNA libraries of wild and modern wheat's following slow drought stress. Plant, Cell \& Environment, vol. 32, no. 3, pp. 220-236. View at Publisher • View at Google Scholar • View at Scopus.

[10] Falconer, D.S. 1989. Introduction to quantitative genetics. 2rd ed John wiley and Sons, New York.

[11] Farooq, S., 2009. "Triticeae: the ultimate source of abiotic stress tolerance improvement in wheat,” in SalInity and Water Stress, M. Ashraf, Ed., chapter 7, pp. 65-71, Springer, Berlin, Germany.

[12] Farshadfar, E., M. Ghandha, M. Zahravi and J. Sutka, 2001. Generation mean analysis of drought tolerance in wheat (Triticum aestivum L.). Acta Agron. Hung, 49: 59-66.

[13] Fischer, R. A. and R. Maurer. 1978. Drought resistance in spring wheat cultivars. I. Grain yield response. Aust. J. Agric. Res., 29: 897-912.

[14] Fleury, D., S. Jefferies, H. Kuchel, and P. Langridge, 2010. Genetic and genomic tools to improve drought tolerance in wheat. Journal of Experimental Botany, vol. 61, no. 12, pp. 3211-3222. View at Publisher • View at Google Scholar • View at Scopus.

[15] Golabadi, M., A.Arzani and S.A.M. Mirmohammadi Maibody, 2006. ssessment of Drought Tolerance in Segregating Populationsin Durum Wheat. African J.of Agricultural Research Vol.1(5): 162-171.

[16] Hallauer, A.R. and Miranda, J.B. 1981. Quantitative Genetics in Maize Breeding. Iowa State Univ. Press, Ames, Iowa. 468pp.

[17] Keller, M., CH. Karutz, J.E. Schmid, P. Stamp, M. Winzeler, B. Kller and M.M. Messmer, 1999. Quantitive trait loci for lodging resistance in a segregation wheat $\mathrm{x}$ spelt population. Theor Appl. Genet., 98: 1171-1182.
[18] Kheiralla, K.A. 1993. Selection response for grain yield and its components in a segregating population of spring wheat. Assiut. J. of Agric. Sci. 24: 87-98.

[19] Mahdy, E.E., K.A. Kheiralla and R.A. Dawood. 1988. Stability analysis of resistance to water-Loss of excised leaf as an indicator of drought resistance in spring wheat. Assiut J. of Agric. Sci., 19 (4): 67-78.

[20] Mather, K. and J. L. Jinks. 1977. Introduction to biometrical genetics. Chapman and Hall, Londan.

[21] Menshawy, A.M.M. 2007. Evaluation of some early bread wheat genotypes under different sowing dates: 2. Agronomic characters. Egypt J. Plant Breed., 11(1): 41-55.

[22] Najafian G, Jafarnejad A, Ghandi A, Nikooseresht R, 2011. Adaptive traits related to terminal drought tolerance in hexaploid wheat (Triticum aestivumL.) genotypes under field conditions. Crop Breeding J. 1: 55-71.

[23] Nanda, G.S., A.B. Afzali and G. Singh. 1990. Genetic analysis of the role of intermitting in an inter varietal cross of breed wheat. Indian J. Genet., 50: 210-215.

[24] Reynolds, M. P., 2006. "Drought adaptation in wheat,” in Drought Tolerance in Cereals. J. M. Ribaut, Ed., chapter 11, pp. 402-436, Haworth's Food Products Press, New York, NY, USA.

[25] Saadalla, M.M. 1994. Response to early generation selection for yield and yield components in wheat. Egypt. J. Appl. Sci., 9 (7): 19-30.

[26] Shamroukh, M. 2006. Breeding for drought tolerance in bread wheat under new land condition in Upper Egypt. Ph.D. Thesis, Minia Univ. Egypt.

[27] Smith, J.D. and M.L. Kinman. 1965. The use of parent-offspring regression as estimation of heritability. Crop Sci., 5(6): 595-596.

[28] Snedecor, G.W. and W.G. Cochran. 1980. Statistical methods.7th ed.Lowa State Unv. Press., Ames., Lowa, U.S.A.

[29] Talebi R, Fayaz F, Naji AM, 2009. Effective selection criteria for assessing drought stress tolerance in durum wheat (Triticum durum DESF). General Appl Plant Physiol. 35: 64-74.

[30] Tammam, A.M., M.S.F. El-Ashmoony, A.A. El-Sherbeny and I.A. Amin. 2004a. Selection responses for drought tolerance in two bread wheat crosses. Egypt. J. Agric. Res., 82 (3): 1213-1226.

[31] Tammam, A.M., M.S.F. El-Ashmoony, A.A. El-Sherbeny and I.A. Amin. 2004b. Breeding for drought tolerance and the association of grain yield and other traits of bread wheat. Egypt. J. Agric. Res. 82 (3): 1227-1241.

[32] Walker, T.T. 1960. The use of a selection index technique in the analysis of progeny row data. Emp. Cott. Gr. Rev., 37: 81-107.

[33] Wiersma, D. W., E. S. Oplinger and S. O. Guy, 1986. Environment and cultivar effects on winter wheat response to ethephon plant growth regulator. Agronomy Journal Vol. 78(5): 761-764.

[34] O’Brien, L., R.J. Baker and L.E. Evans, 1978. Response to selection for yield in F3 of four wheat crosses. Crop Sci., 18: 1029-1033.

[35] Wells, W.C. and K.D. Kofoid, 1986. Selection indces to improve an intermating population of spring wheat. Crop Sci., 26: 11041109.

[36] Smith, E.L., 1976. The genetics of wheat architecture. Ann. Oklahoma Acad. Sci., 6: 117-132. 